Research Article

\title{
Development Assessment of the Coal Industry of China Based on the Minimum Deviation Comprehensive Weight Evaluation Model
}

\author{
Shihua Ren $\mathbb{D}^{1,2}$ Dezhi Zheng $\mathbb{D}^{2},{ }^{2}$ Yang Qu $\mathbb{D},{ }^{3}$ Rongjun Qin $\mathbb{D}^{4},{ }^{4}$ Xiaomiao Jiao $\mathbb{D},{ }^{2}$ \\ and Jinyan Bai $\mathbb{B D}^{5}$ \\ ${ }^{1}$ School of Management, China University of Mining and Technology (Beijing), Beijing 100083, China \\ ${ }^{2}$ China Coal Research Institute, Beijing 100013, China \\ ${ }^{3}$ Coal Industry Planning Institute, Beijing 100120, China \\ ${ }^{4}$ China Coal Economic Research Association, Beijing 100013, China \\ ${ }^{5}$ China Coal Technology \& Engineering Group Corp., Beijing 100013, China
}

Correspondence should be addressed to Dezhi Zheng; zhengdezhi@mtghy.com

Received 16 November 2021; Accepted 2 December 2021; Published 13 December 2021

Academic Editor: Yonghong Wang

Copyright $(2021$ Shihua Ren et al. This is an open access article distributed under the Creative Commons Attribution License, which permits unrestricted use, distribution, and reproduction in any medium, provided the original work is properly cited.

Coal is the most reliable energy resource in China and has been in existence for a long time. The development model of coal industry is of great significance to carbon emission and environmental protection. In order to evaluate the development mode of China's coal industry, this paper presents the constructed evaluation index system of the development mode of the coal industry from two dimensions, demand pull and factor drive. And, coal consumption is the measurement index of demand pull and selecting resources, capital, technology, human resources, and the energy system form the measurement index of factor drive. By analyzing the evaluation index system of the coal industry development mode and optimal evaluation method, the minimum deviation comprehensive weighting evaluation model, based on the analytic hierarchy process (AHP), and entropy are constructed. The evaluation results show that the coal industry has continued the factor driven growth, driven by demand, in the past decades. Finally, the study analyzes the changes and challenges of the development of China's coal industry from four aspects, development power, development mode, development effect, and development bottleneck, to provide support for revealing the internal mechanism of the development mode of China's coal industry.

\section{Introduction}

The development of the coal industry is closely related to social economy and energy demand and is affected by multiple factors, such as available resources, available capital, current technology, manpower, and the country's energy system. Energy demand is the driving force behind the development of the coal industry. Evaluating the development mode of the coal industry and revealing the impacts that various factors have on the development of the coal industry and its internal mechanisms have theoretical and practical significance for understanding and promoting the transformation of the development mode of the coal industry [1-5].

At present, qualitative and quantitative evaluation methods mainly include the analytic hierarchy process and the entropy method, which are applied in many fields [6-8]. Naghadehi et al. proposed a fuzzy model, based on the combination of the fuzzy analytic hierarchy process and an advanced type of traditional analytic hierarchy process, which selects the best mining scheme by using effective main criteria and considering the subjective judgment of decisionmakers [9]. Underground mining method selection is one of the most important decisions in mining engineering. The selection of appropriate underground mining methods for deposit mining is very important for all stages of mining operations. Yavuz introduced two similar, multiattribute decision-making methods-analytic hierarchy process and fuzzy multiattribute decision-making method-used to select the best underground mining method of Istanbul's lignite mine; they also performed a sensitivity analysis for 
each method [10]. Shi et al. proposed an advanced optimization classification method based on fuzzy analytic hierarchy process and tunnel seismic prediction to accurately predict the classification of surrounding rock. The comprehensive weighting method is used to determine the weight of the evaluation index, and the fuzzy analytic hierarchy process model is used for optimal classification of surrounding rock [11]. Based on expert investigation, a three-level, eighteen factor risk evaluation index system for tunnel construction safety evaluation is established through the improved analytic hierarchy process [12]. Qualitative analysis is based mainly on the judgment, knowledge, and experience of one or more experts. In the case of limited available information, the subjective probability based on general professional experience, knowledge, and expert opinions can be used as the basis of analysis. Due to the frequent lack of quantitative data, experience and intuition have always been at the core of mining decision-making [13]. $\mathrm{Bi}$ et al. provide an effective method for rectifying potential gaps in the data. The index system is established as the basis of evaluation, and the quantitative evaluation results are obtained by using the matter-element extension method. Centering around the weight value of each index in the matter-element extension method, a comprehensive weight calculation method, based on vague set and entropy, is proposed [14]. In project management, this is an important method to comprehensively evaluate a project's safety risks based on information provided by experts [15-17]. However, the subjective weighting methods, such as analytic hierarchy process and expert consultation, have certain subjective randomness due to the experience or tendencies of decisionmakers. The objective weighting methods, such as entropy and grey correlation, make full use of the objective information available, but it is easy to ignore the experience information of experts. Therefore, the use of a combination of quantitative and qualitative evaluation methods, if widely used in various engineering fields, could enhance the evaluation index system [18-21].

To improve the high-tech level of the coal industry, it is necessary not only to find new methods of upgrading power and creating new competitive advantages, an emerging practical problem in the coal industry, but also to solve the core issue of efficiently transforming the economic growth mode of the coal industry in the $12^{\text {th }}$ Five Year Plan, which is key for solving China's energy supply and energy security problem. The coal industry is an important part of China's national economy and provides necessary energy and other resources for economic development. To alleviate China's environmental pressure, it is imperative that changes be made to the national structure of the coal industry through reasonable analysis. Only then, can China realize healthy development of its coal industry, which is of great significance for ensuring national energy security and achieving the objectives of environmental and atmospheric governance [22-24].

Based on factor driven theory, system theory, resource allocation theory, and synergy theory, this study constructs the evaluation index system of the development mode of the coal industry and the minimum deviation comprehensive weighted evaluation model, based on analytic hierarchy process entropy, using the weight calculation method, combining quantitative and qualitative methods, with the aim of providing support for revealing the internal mechanisms of the development mode of the coal industry in China.

\section{Methodology}

\subsection{Model of Evaluation of Development Mode of the Coal Industry}

2.1.1. Comprehensive Evaluation Index System. According to the factor driven theory, system theory, resource allocation theory, synergy theory, and other related theories, an index system for the evaluation of the development mode of the coal industry is constructed from the two dimensions of demand pull and factor drive (Figure 1).

Coal consumption is the driving force that best reflects demand. "Coal consumption" was selected as the measurement index of demand pull. Capital, resources, manpower, technology, and energy system, five key elements driving the development of the coal industry, were selected as the measurement index of factor drive. Among the resource indicators, "available resources" indicator was selected as the specific one to measure the resource scale and resource availability potential. Among the capital indicators, "industry fixed asset investment" was selected as the specific indicator to measure the investment scale and investment intensity. Among the technical indicators, there are many indicators to measure the technical level. To judge the overall technical level, the qualitative indicator of "comprehensive technical level" was selected for grading, as it covers multiple subitems such as recovery rate, mechanization degree, and waste resource utilization rate. In the manpower index, "number of employees in the coal industry" was selected as the specific index to measure the scale of employees. In the system indicators, since the system is concentrated in the policy field, "policy suitability" was selected as the specific indicator, as it covers multiple subitems such as policy applicability, policy intensity, and policy implementation effect, and the value is comprehensively evaluated by an expert scoring method.

2.1.2. Minimum Deviation Comprehensive Weighting Evaluation Model. The evaluation model of the coal industry development mode was constructed according to the evaluation index system and optimal evaluation method of the coal industry development mode. The model uses the hierarchy process and entropy method to determine the subjective weight $u_{j}$ and objective weight $v_{j}$ of each index. The minimum deviation combination weighting method was used to calculate the comprehensive weight $w$ of resources, capital, technology, manpower, energy system, and other contributing factors, respectively, determine the difference between demand pull and factor drive on the development of coal industry, and quantitatively describe the internal impact mechanism. The minimum deviation comprehensive weighting evaluation model is shown in Figure 2. 


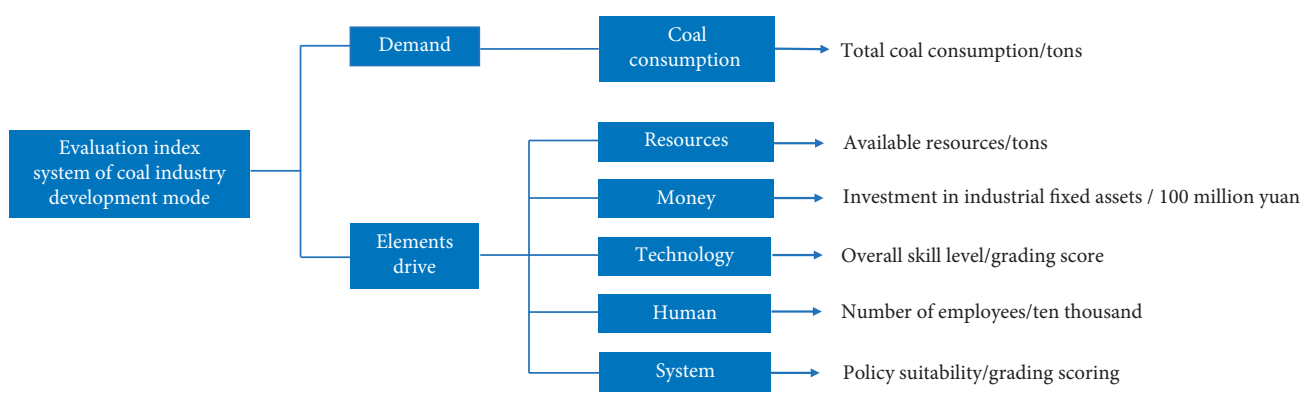

Figure 1: Assessment index system of development mode of the coal industry of China.

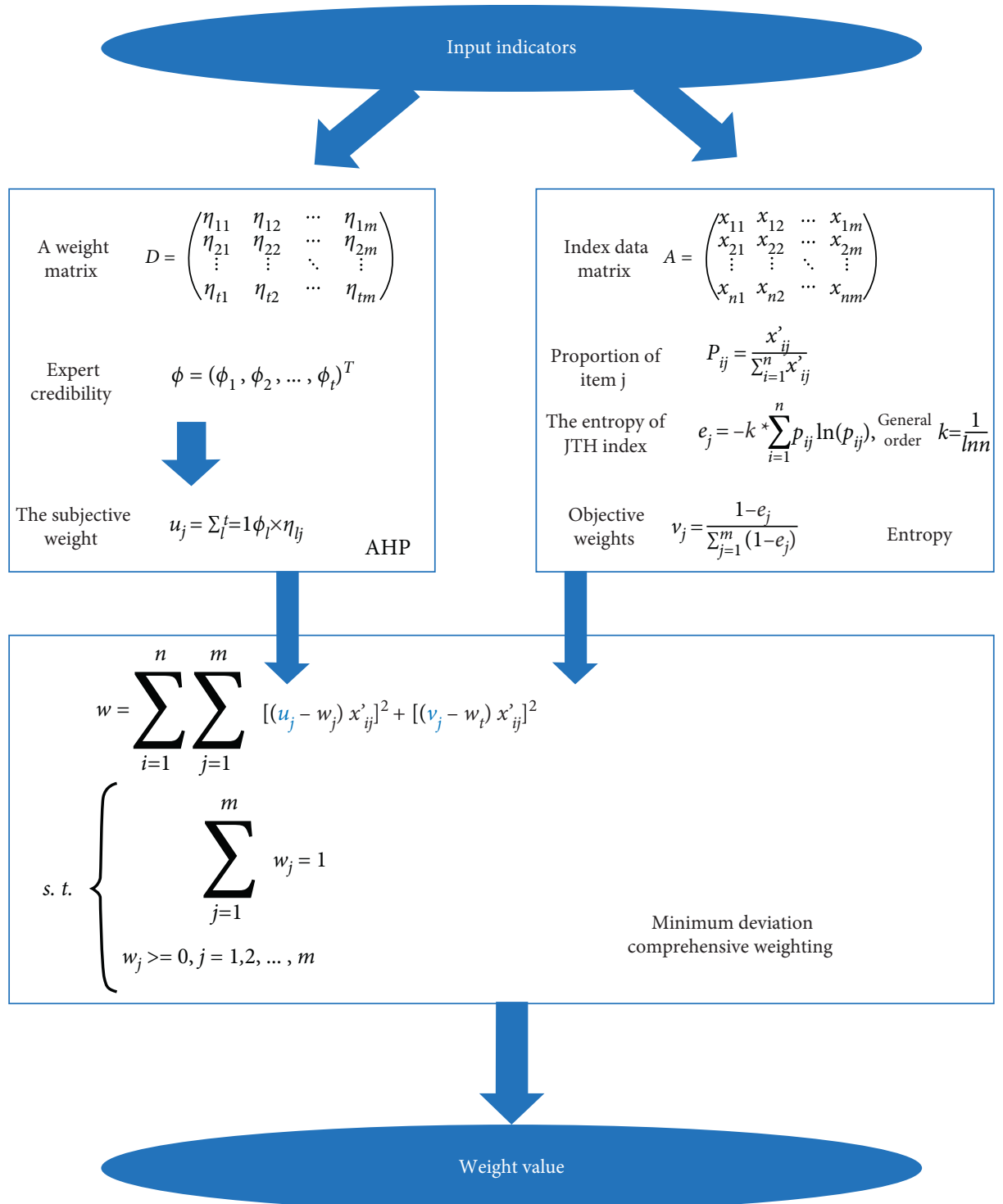

FIgURe 2: Minimum deviation comprehensive weighting evaluation model ( $w$ is weight, e is entropy, and $P$ is probability).

\section{Case Study}

To reform and transform future development mode of the coal industry, an understanding of the laws (brought out as a response to the past few decades' rapid coal industry developments), power sources, driving factors, and sustainability of development is required. Since the reform and opening of China, with the development of heavy industry and the acceleration of urbanization, the social economy of China has developed rapidly, as has the demand for energy. 
Coal has attracted much attention and investment, as China's main source of energy, with the continuous growth of energy demand. Resources, capital, technology, manpower, policies, and other production considerations continue to accumulate in the coal industry, promoting the leapfrog development of the coal industry.

Using the established evaluation model, the review and evaluation of the development mode of the coal industry show that the coal industry has continued the demand driven, factor driven growth in the past few decades. As a core factor, a rate of $39.62 \%$ was contributed by demand. And rates of 10.19\%, 15.28\%, 12.36\%, $13.21 \%$, and $9.34 \%$ were contributed by resources, capital, technology, manpower, energy system, and other factors, driving the development of the coal industry. However, after experiencing rapid development, the sustainability of driving factors is facing challenges, and the existing development mode of the coal industry has fallen into a bottleneck (Figure 3).

\subsection{Development Power}

3.1.1. Economy. Since the reform and opening of China, the industrial scale has increased rapidly, along with the economy. According to the process of economic system reform, it can be divided into four stages:

From 1978 to 1992, the exploration stage of market economy was taking place. The economy was dominated by planned economy and supplemented by market regulation. The average annual growth rate of China's economy was $9.46 \%$.

From 1993 to 2002, the market economy was established. China had entered the establishment period of a socialist market economy, with Chinese characteristics. The market vitality had been fully stimulated and the economy had developed vigorously. At this stage, the economy had an average annual growth rate of $9.84 \%$.

From 2003 to 2016, the socialist market economic system was improved. The important goal of this stage of reform was to give greater play to the basic role of the market in resource allocation, enhance the vitality and competitiveness of enterprises, and achieve an average annual economic growth of $9.59 \%$.

From 2017 to now, the economy has transitioned from high-speed growth to high-quality development. Since the $19^{\text {th }}$ National Congress of the Communist Party of China, China has entered a new era of socialism, with Chinese characteristics, and the economy has gradually transitioned from high-speed and medium high-speed growth to high-quality development with medium high-speed growth.

The annual economic growth rate of the first three stages is high and low, and the average economic growth rate of each stage is about $9.6 \%$. In the fourth stage, although the economic growth rate decreased, the absolute growth of gross domestic product (GDP) constantly grew every year.
3.1.2. Energy. Since the reform and opening of China, although energy consumption per unit GDP has decreased year by year, the elasticity coefficient of energy consumption has been maintained at 0.5 , which shows the relationship between economic growth and energy consumption. The historical experience of major developed countries also shows that the elasticity coefficient of energy consumption will remain at a high level before the completion of industrialization.

According to the four stages of the process of economic system reform, the elasticity coefficient of energy consumption in different stages represents different defining characteristics. From 1978 to 1992 , the average energy consumption elasticity coefficient was 0.77 . At this stage, the economic base is low, the development growth rate is high, and the energy consumption elasticity coefficient is relatively high. From 1993 to 2002, the elasticity coefficient of energy consumption decreased, with an average value of 0.46 . From 2003 to 2016, due to the rapid growth of high energyconsuming industries and the rapid increase of energy consumption, the average elastic coefficient of energy consumption rebounded to 0.69 , and the value was even higher than 1 for three consecutive years, from 2003 to 2005. Since 2017, China has taken the initiative to change the mode of economic development and promote the revolution of energy production and consumption. The growth rate of energy consumption and economic growth have both decreased, and the average elasticity coefficient of energy consumption has dropped to 0.56 .

3.1.3. Coal. Due to energy resource endowment, international energy prices, and international situation, China mainly depends on local energy, and coal is the only energy source which can be relied on. At the beginning of the founding of new China, coal consumption accounted for more than $90 \%$ of total primary energy consumption. The economy and coal consumption depended on and promoted each other. National coal consumption increased from 400 million TCE in 1978 to 2.829 billion TCE in 2020, an increase of $600 \%$. From 1978 to 1992 , with the implementation of the reform and opening-up policy, the demand for energy from coal increased sharply, and the coal consumption increased steadily, with an average annual growth rate of 5.6\%. From 1993 to 2002, affected by the Asian financial crisis, China was in a period of economic fluctuation and adjustment. Coal consumption fluctuated from 866 million TCE to 1.162 billion TCE, an increase of $34.2 \%$. The consumption growth rate was negative from 1997 to 1999. From 2003 to 2016, driven by the rapid economic growth, coal demand also increased rapidly, and consumption was nearly doubled, with an average annual growth rate of $6.4 \%$. Since 2017, due to the adjustment of the economic development mode, the growth rate of coal consumption has decreased, and coal consumption has entered the platform period, with an average growth rate of $1.2 \%$ (Figure 4). 


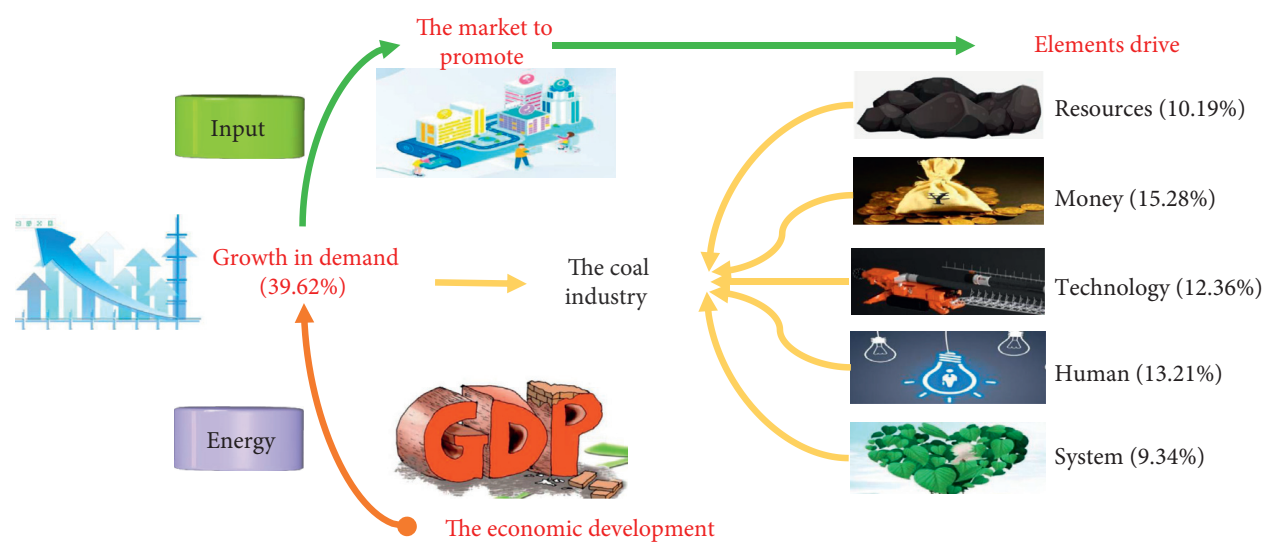

FIGURE 3: Development mode of the coal industry in the past decades.

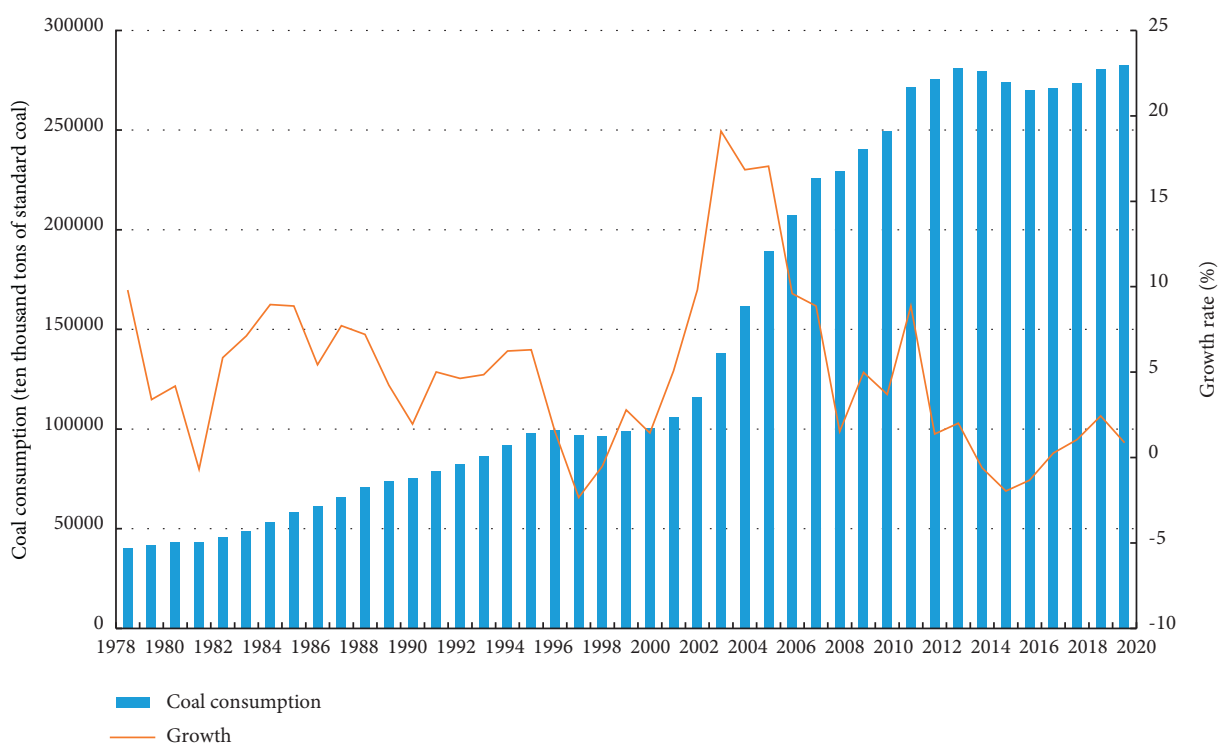

FIGURE 4: Coal consumption and growth rate from 1978 to 2020 in China.

\subsection{Development Mode}

3.2.1. Resources. With the increase of resources explored in the western region, the breadth and depth of coal development are gradually shifting from the east to the west. The coal industry was mainly distributed in the eastern regions of China, where there are 21.53 million tons for output and $66.4 \%$ of the national coal output. The coal output of Liaoning Province was the first among all provinces in China with 5.44 million tons. In that year, the coal output in the central region was 6.79 million tons, accounting for $21 \%$ of the national coal output, and the coal output in the western region was 4.11 million tons, accounting for only $12.7 \%$ of the national output. In 2008, the coal output in the western region of China reached 1.171 billion tons, accounting for $43 \%$ of the national output, surpassing the central region for the first time and becoming the main coal supplier and important commercial coal transference area in China. The coal output in the central region is 1.073 billion tons, accounting for $40 \%$ of the national output. The coal output in the eastern region is 466 million tons, accounting for $17 \%$ of the national coal output. The proportion of coal output in the eastern region continues to decline to this day.

In 2018, the coal production in Western China reached 2.283 billion tons, accounting for $59.38 \%$ of the national coal output, the coal production in Central China was 1.292 billion tons, accounting for $33.63 \%$ of the national output, and the coal output in the eastern region is 269 million tons, accounting for $6.99 \%$ of the national coal output. Coal development is further concentrated in the western region (Figure 5).

3.2.2. Capital. Capital is the foundation of the development of every industry. Only through continuous inflow can the industry develop. The coal industry has experienced a roller coaster fluctuation process from rapid inflow, to a sharp decline in investments. 2000 to 2002 was a period of reforming and extricating the coal industry from difficulties. At this stage, the coal industry is vigorously improving conditions of small coal mines, focusing on solving deepseated problems such as structural contradictions, and the 


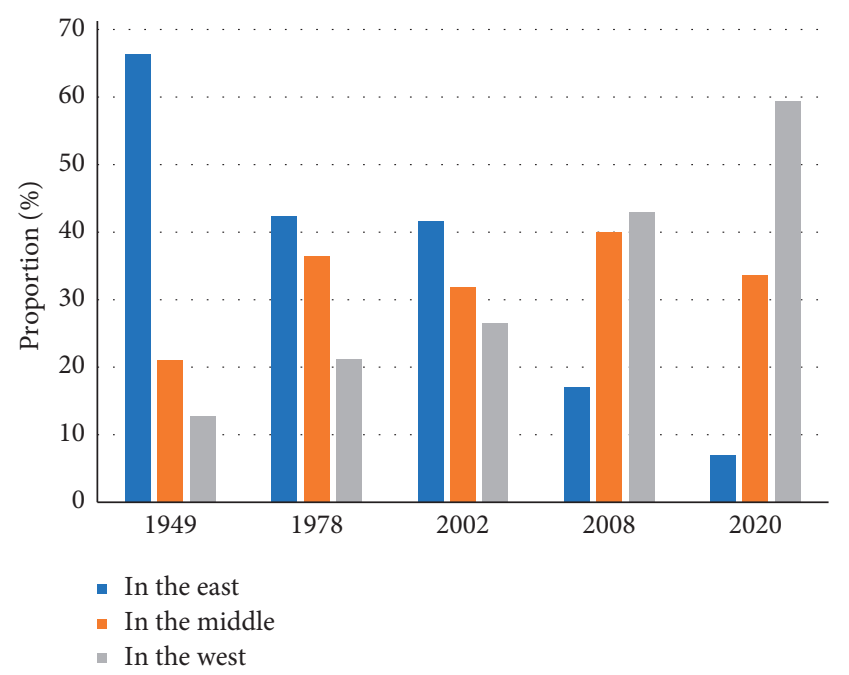

Figure 5: Coal production in different regions of China from 1949 to 2020 .

number of total investments is gradually increasing. 2003-2012 was a golden decade of rapid development for the coal industry. At this stage, with the rising demand of the coal market and the profitability of coal enterprises increasing, a large amount of social capital entered the coal industry. During this time, the total number of investments increased rapidly, from 43.7 billion yuan in 2003 to 537 billion yuan in 2012, 12 times what it was in the past decade, with a compound growth rate of $34 \%$. As a result, many projects started on shaky ground, the coal production capacity increased rapidly, and the market overheated. From 2013 to 2016, the national coal industry faced overcapacity, weak demand, falling prices, many losses, and great operating pressure, resulting in the decrease of fixed asset investment in the coal mining and dressing industries for five consecutive years. Since 2016, the coal industry has entered the de-capacity stage. By the end of 2019, the main objectives and tasks of coal de-capacity have been essentially completed. The coal industry has changed from total de-capacity to systematic de-capacity and structural excellent capacity. At the same time, with the continuous improvement of industrial benefits, the fixed asset investment in the coal industry is beginning to be picked up (Figure 6).

3.2.3. Technology. Through the introduction, digestion, absorption, and reinnovation of the coal industry, many scientific researchers have investigated a series of key problems in the technological transformation from miningfocused technology to safety guarantee technology, from process to complete equipment, and from single technology to system integration and achieved fruitful results. The degree of coal mining mechanization in China started late. In the 1960s, the degree of mechanization was less than $10 \%$. With the continuous progress of science and technology in China, the degree of coal mining mechanization in large coal enterprises increased from $3.06 \%$ in 1955 to $98.03 \%$ in 2019. At the same time, scientific and technological innovation in the coal industry has gradually upgraded from tracking and imitating to paralleling and leading. Intelligent mining technology and equipment, large-scale mine construction, fully mechanized top coal caving mining of extra thick coal seams, and other technologies have reached the international leading level. China has built more than 200 intelligent coal mining faces and created a new intelligent mining mode of "one person inspection and no operation." In addition, the complete sets of large-scale, fully mechanized mining technology and equipment have been exported to Russia, Ukraine, and many other countries realizing the subversive transformation of technology and equipment from input to output.

3.2.4. Manpower. The coal industry has many employees, as it is a typical labor-intensive industry. Before 2000, the average number of employees in the coal mining and washing industry was less than 4 million. With the opening of the "golden decade" of the coal industry, this number exceeded 4 million in 2004 and 5 million in 2008 and reached an all-time high of 6.11 million in 2013. With the industry's overcapacity and increasing losses, coal enterprises have implemented cost reduction and capital increase and started personnel diversion. The average number of coal employees began to fall after 2014. According to the data of the fourth national economic census, in 2018 , the number of employees in the coal industry was 3.473 million, which is still the highest number of employees in the world, accounting for $58.27 \%$ of the total number of mining industry. Among all 40 industries in the secondary industry, the number of people in the coal industry ranks $12^{\text {th }}$, accounting for $3 \%$ of the total number of people in the secondary industry. Combined with the output data of that year, it can be calculated that the per capita output of China's coal industry is about $1059.6 \mathrm{t}$, which is far lower than the per capita output of $12800 \mathrm{t}$ in the US coal industry (in 2018, the US raw coal output was 684 million $t$ and 53583 employees). China's coal industry is still driven by labor-intensive development.

\subsection{Development Achievements}

3.3.1. Supply. After years of development, the productivity level of the coal industry has increased dramatically. The security and stable supply guarantee capacity has been greatly improved, meeting the needs of sustained, rapid development of the national economy, and the coal supply guarantee capacity has been significantly improved (Figure 7). From 2016 to 2019, the newly identified resource reserves of coal increased by 227.9 billion tons. The national coal resource development and production layout have been continuously optimized, and the focus of resource development has gradually shifted to regions with good resource endowment, excellent mining conditions, and low production cost. The focus of coal production has been continuously optimized, the production capacity has been gradually concentrated, and total advanced production capacity has been greatly increased. Regional centralized development of the coal industry has been gradually 


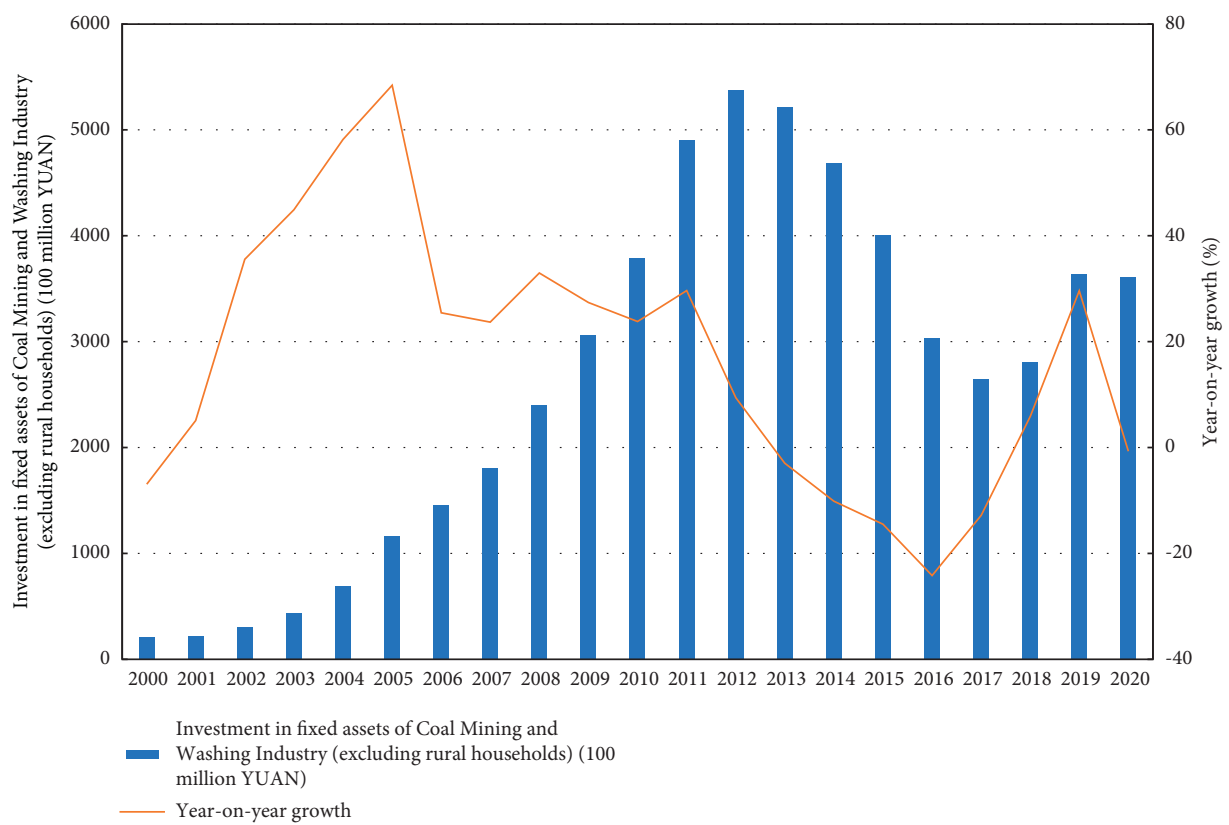

Figure 6: Fixed assets investment of coal mining and dressing industry from 2000 to 2020 in China.

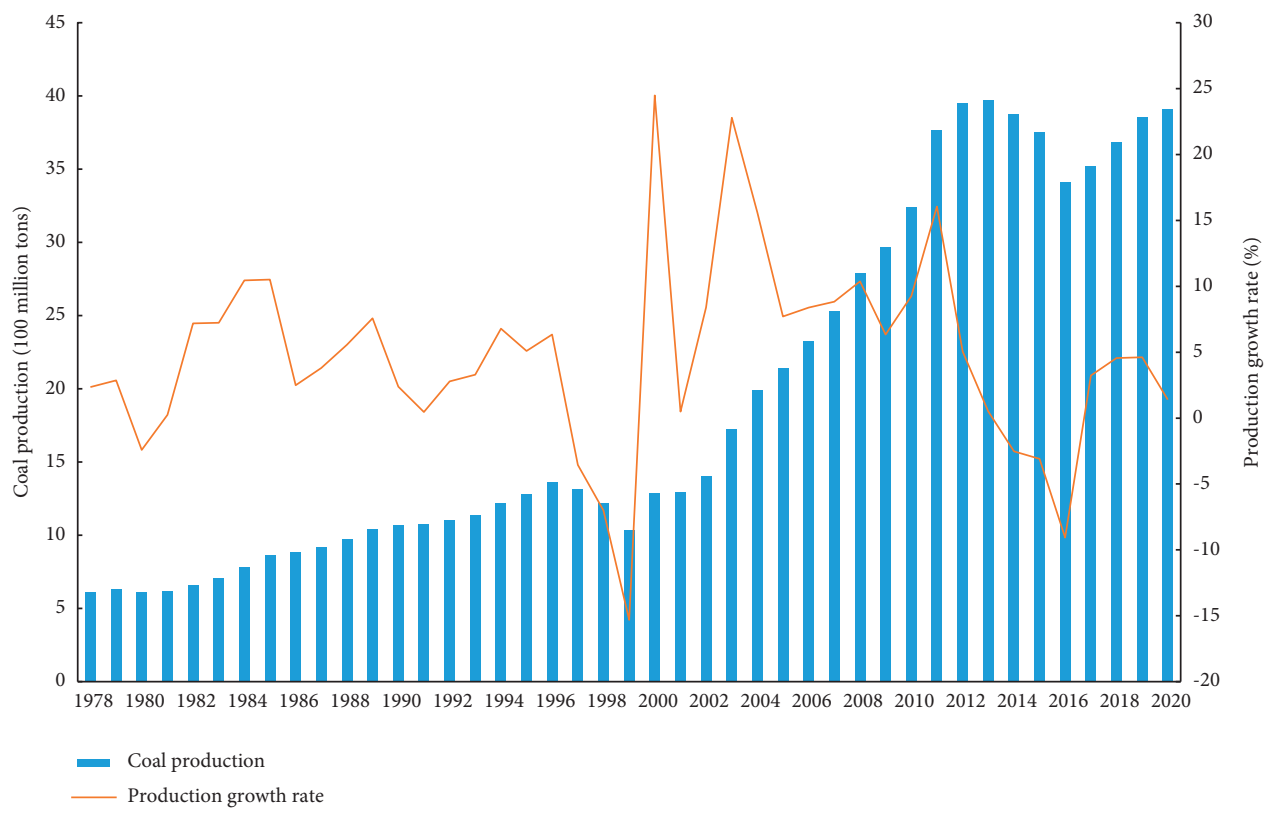

Figure 7: Coal output from 1978 to 2020 in China.

established. As the main coal producing areas, the central and western regions have become more and more prominent in their strategic position. The coal output of Shanxi, Shaanxi, and Inner Mongolia accounts for more than $70 \%$ of the total output of the country. The construction of large coal bases has been continuously promoted. The number of coal mines in China has decreased from more than 80000 in the early stage of reform and opening of China to 4700 by the end of 2020, and the advanced production capacity has increased by 600 million $\mathrm{t} / \mathrm{a}$. The national coal mine production capacity is 4.1 billion $\mathrm{t} / \mathrm{a}$, and the average single well (mine) production capacity has increased to more than 1.1 million $\mathrm{t} / \mathrm{a}$. Large modern coal mines have become the main body of national coal production. More than 1200 large modern coal mines, with an annual output of more than 1.2 million tons, have been built in China, accounting for $80 \%$ of the country's output. Among them, 52 coal mines, with an annual output of 10 million tons, have been built, with a production capacity of 820 million t/a. The national system of scientific planning, rational development, modern production, and clean, efficient utilization of coal resources has been essentially completed. 
3.3.2. Efficiency. In recent years, the coal industry has continuously improved the overall work efficiency of raw coal production by optimizing development layout, developing high-quality production capacity, and promoting mine mechanization and intelligent mining. Some coal mines have even reached the international advanced level. Coal resources are deeply buried in coal seams, and the proportion of open-pit coal mines with favorable congenital conditions is less than $12 \%$. The mines with difficulties account for the vast majority. In addition to the unfavorable conditions, such as many fault structures, thin coal seams, and steep dip angles (which can lead to excessive horizontal stress conditions), some mines in China are also accompanied by disasters such as gas, water, fire and rock burst, limited mining conditions, and frequent safety accidents, which restrict the mining efficiency. However, with the improvement of coal technology, the coal production efficiency has increased from $325.59 \mathrm{t} / \mathrm{a}$ in 2000 to $1921.19 \mathrm{t} / \mathrm{a}$ in 2020 , an increase of $490 \%$ (Figure 8). From 2013 to 2020, the annual output of raw coal has been maintained at 3.6 billion tons. But, during this period, the number of employees has dropped sharply from 6.11 million to 4.08 million and 2.03 million, a decrease of $66.8 \%$ and an average annual decrease of $11.1 \%$. Compared with 2013 , the coal industry completed more workload in 2020 with less than $33 \%$ of the original personnel. At the same time, some coal mines have obvious advantages in work efficiency, and the efficiency of the coal industry has been greatly improved.

3.3.3. Safety. Due to the problems of complex coal mine geological conditions, many natural disasters, mining difficulties, and frequent accidents, the coal mine safety regulations gradually improved, and the mortality rate per one million tons has decreased year by year. Overall, the development process of coal mine safety in China is divided into three major periods: $1949-1977$ is the period of sharp fluctuation of coal mine safety. During this period, the core task of the coal industry was to ensure coal production and supply. The coal mines built were mostly small or mediumsized, and the coal mine production technology and equipment were relatively backward, resulting in frequent coal mine accidents. The mortality rate per million tons fluctuated between 4.32 and 22.28, and the safety situation was very serious. From 1978 to 2002, the level of coal mine safety continued to improve. During this period, priorities changed from planning mining to ensure coal supply to promoting safe and efficient coal mining through technological progress. Significant progress was made in the construction of large coal bases. The mortality rate per million tons decreased from 9.44 in 1978 to 4.94 in 2002. The overall situation of coal mine safety continued to improve steadily throughout the next several years. 2003-2020 saw a period of rapid improvement to coal mine safety. During this period, after the "golden decade" of industry development, coal mining enterprises' investment in safety production has increased continuously, the degree of coal mining mechanization has increased significantly, and key technologies and equipment for major disaster management have been popularized and applied. The death rate per million tons decreased rapidly from 3.71 in 2003 to 0.059 in 2020 (Figure 9).

3.3.4. Quality. Over the past 60 years, compared with coal production, the increase of the raw coal selection rate in China has increased. In 1952, the raw coal selection rate was approximately $4.4 \%$, and the annual output of washed coal was only a few million tons. In 2020, China's coal selection rate has reached approximately $74.1 \%$ (Figure 10). The coal preparation process developed from jigging in the 1950s to the 1970s, to the process of jigging, roughing, and dense medium cyclone cleaning in the 1980s and then to the coexistence of jigging, dense medium separation, water medium cyclone separation, moving screen jigging, air separation, autogenous medium separation, and microbubble flotation in the 1990s. In recent years, with the continuous reduction of capital investment and production cost of heavy medium coal preparation process, after solving the problems of wear resistance of equipment and pipeline, medium recovery, and efficient pumping equipment, heavy medium coal preparation technology has developed rapidly in China. Its characteristics of easy operation and high efficiency have made it more and more popular, and it has become the leading process. In the $21^{\text {st }}$ century, coal preparation, the frontier of clean coal technology, has obvious effects on the improvement of coal quality and utilization efficiency, reduction of ineffective transportation, and reduction of coal pollutant emission. Coal preparation has entered a period of great development. The raw coal capacity of the average coal preparation plant increased from 522 million t/a to 2896 million t/a with an average annual increase of 100 million $t$ from 2000 to 2020 .

\section{Discussion}

4.1. Recoverable Resources of a Shallow Economy Have Been Greatly Reduced. The guaranteed degree of coal resources is low, the recoverable resources of shallow economy are greatly reduced, and the coal resources that can be economically developed and utilized in the future are not rich, which has become the bottleneck restricting the construction of coal modernization. Firstly, after more than 50 years of development in the eastern Huang Huai area, which is rich in coal resources, there are few coal resources left in the Shanxi formation with excellent shallow coal quality, low sulfur content, and other harmful elements and simple hydrogeological conditions. More are turning to the development of the lower coal group, dominated by the Taiyuan formation, which has high sulfur content and complex conditions of Ordovician and Taiyuan limestone water. Secondly, many provinces plan to withdraw from coal production entirely in the next few years. For example, Hebei's coal production capacity withdrew by more than $40 \%$ from 2016 to 2019. Jiangxi and Chongqing also plan to significantly reduce coal production and eventually withdraw from the coal production industry. Thirdly, coal resources within the ecological red line will no longer be 


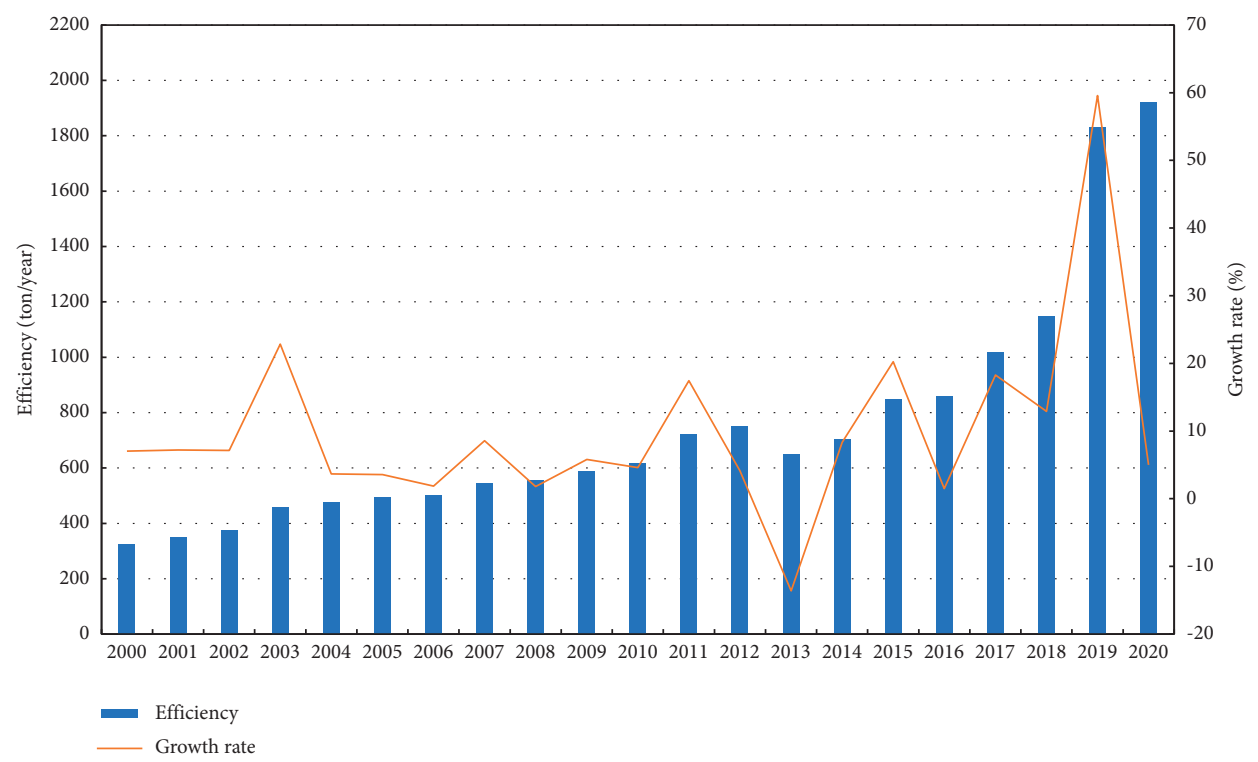

Figure 8: Coal production efficiency of China since 2000.

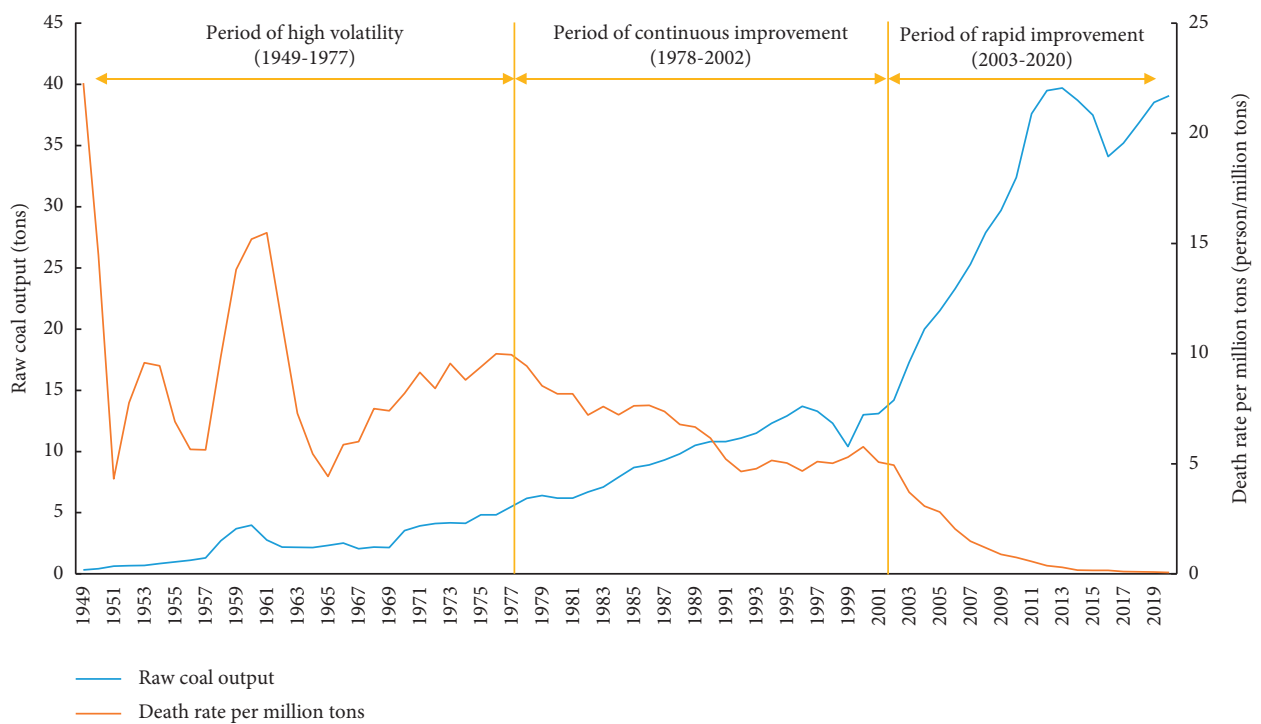

FIgure 9: Coal production and death rate per million tons in China.

exploited. From the current situation, many coal resources in Guizhou, Inner Mongolia, Shanxi, Shaanxi, and other provinces will be included in the ecological red line and can no longer be mined. Finally, among the proven 5.57 trillion $t$ coal resources, 2.95 trillion $\mathrm{t}$ of them is buried below $1000 \mathrm{~m}$, accounting for $53 \%$ of the total coal resources, which is difficult to develop.

\subsection{Lack of Independent Innovation, Difficult to Support} Future Needs. Coal science and technology play a decisive role in the development of the coal industry and are the foundation of industry development. Although the coal science and technology level have made great progress and significantly improved, there is still a large gap compared with the world's energy science and technology power. The lack of core technology in the coal industry and the dependence on imports of key equipment and materials are still prominent. Based on the principles, standards, and specifications of the United States, the European Union, and other countries, the technical equipment of coal industry was developed. Generally, the process of complete introduction, partial domestic supporting, and domestic R \& D and manufacturing is adopted. The core components are independently developed. At present, almost all complete machines such as shearers, scrapers, conveyors, and scraper transfer machines in China can be assembled. However, many core components are still imported. For example, the large scraper conveyor produced in China is internationally leading, but the reducer above $2000 \mathrm{~kW}$ still needs to be purchased from PW, a company in Germany. The $5 \mathrm{~m}$ diameter raise boring machine is internationally leading, but 


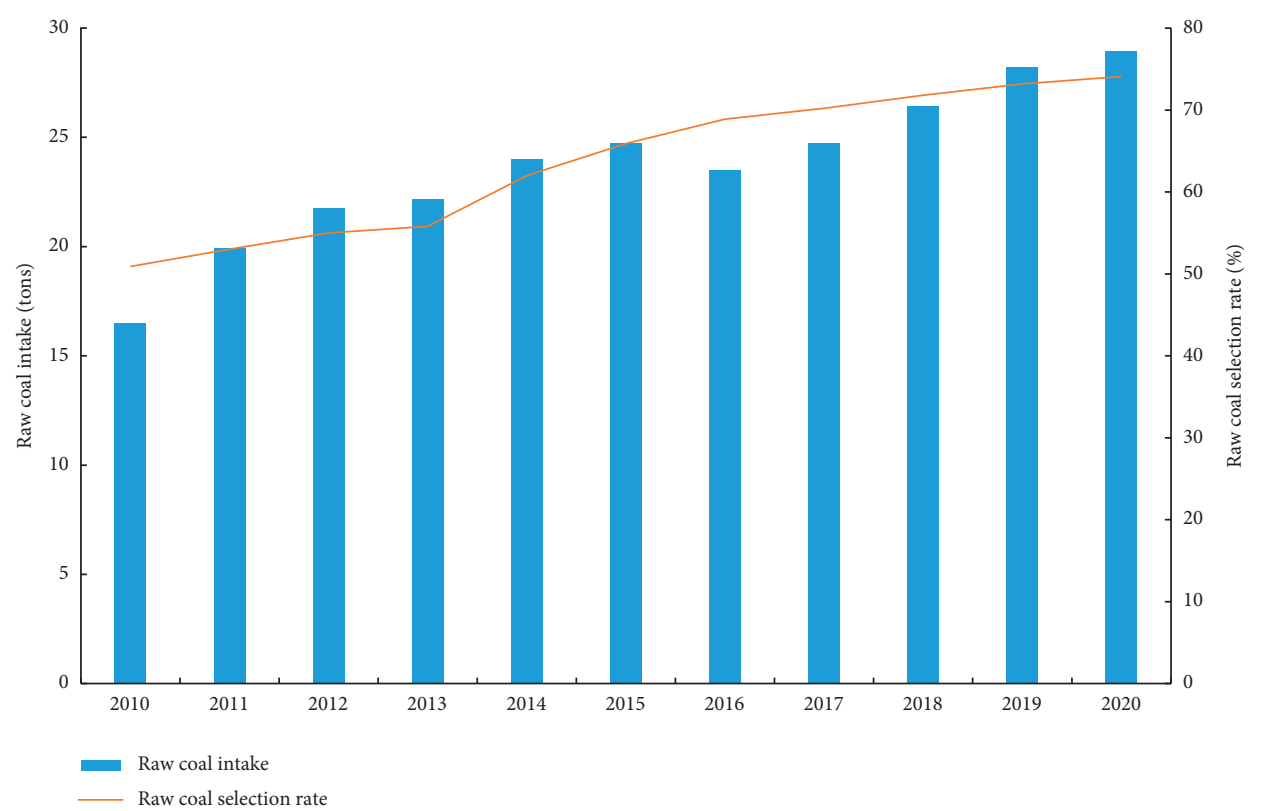

FIgURE 10: Coal selection rate and quantity in China from 2010 to 2020.

the hydraulic motor still needs to be purchased from Buckland, a company in France, the $8.8 \mathrm{~m}$ shearer is internationally leading, but the high-speed and large load bearing still needs to be purchased from the United States, etc. We must understand the huge gap in the scientific and technological levels regarding the coal industry, especially high-end manufacturing. Many technical pieces of equipment are still controlled by people, and there is insufficient independent innovation, which makes it difficult to support the future development of the coal industry.

\subsection{Employees Are Too Old and the Improvement of Personnel} Quality Is Limited. The contradiction between the low overall quality of employees in the coal industry and the demand for high-quality personnel is becoming more and more prominent. Although the number of employees in the coal industry is large, the overall quality is low. With the continuous improvement of industry automation and intelligence, the requirements of industry development on personnel quality will be higher and higher. As it is, the existing human structure level cannot meet the needs of industry development. First, the employees are too old, and the reserve labor force is insufficient. The proportion of people over 40 years old in mining industry accounts for $56.8 \%$, exceeding the average level of the whole industry. Second, the overall quality is not high and there is a shortage of senior technicians. At present, the employees are mainly technical secondary school students, nearly half of them have an education at or below the technical secondary school level, and less than $30 \%$ have a college education or above. The demand for high-quality and high-tech talent is becoming stronger and stronger. In the United States, only those with a professional education can enter the coal industry. Nearly $90 \%$ of employees come from vocational schools. The employees have high professional quality and rich practical experience. These high-quality talent teams support the intelligent level of the American coal industry. At present, the personnel structure, with low education, in the coal industry cannot meet future needs. There is a prominent contradiction between the large number of surplus personnel and the shortage of senior skilled talents.

\section{Conclusion}

From the two dimensions of demand pull and factor drive, this paper presents the evaluation index system of the development mode of the coal industry, with "coal consumption" as the measurement index of demand pull. Select resources, capital, technology, manpower, and energy system as factor driven measurement indicators. According to the evaluation index system and optimal evaluation method of coal industry development mode, the model of the coal industry development mode evaluation is constructed. The model uses the analytic hierarchy process and entropy method to determine the subjective weight $u_{j}$ and objective weight $v_{j}$ of each index.

Based on the constructed model, the development mode of the coal industry is reviewed and evaluated. The results show that the coal industry has continued the demand driven factor driven growth in the past few decades. Demand pull is the core factor, with a contribution rate of $39.62 \%$; resources, capital, technology, manpower, energy system, and other factors specifically drive the development of the coal industry, with contribution rates of $10.19 \%, 15.28 \%$, $12.36 \%, 13.21 \%$, and $9.34 \%$, respectively.

After experiencing rapid development, the sustainability of driving factors is facing challenges. The bottlenecks of the existing development mode of the coal industry are analyzed in detail from five aspects: resources, capital, technology, manpower, and system. 


\section{Data Availability}

The datasets generated during the current study are available from the corresponding author on reasonable request.

\section{Conflicts of Interest}

The authors declare no conflicts of interest.

\section{Authors' Contributions}

The manuscript was approved by all authors for publication.

\section{Acknowledgments}

This work was supported by China Coal Technology and Engineering Group (Grant number 2018-2-ZD008) and the strategic research and consulting project of Chinese Academy of Engineering (Grant number 2021-XY-25).

\section{References}

[1] Q. Li, "The view of technological innovation in coal industry under the vision of carbon neutralization," International Journal of Coal Science and Technology, vol. 1-11, 2021.

[2] M. Zhou and T. Hu, "Analysis of carbon emission status under the carbon neutral target in China for Earth's atmospheric balance," IOP Conference Series: Earth and Environmental Science, vol. 804, no. 4, Article ID 042082, 2021.

[3] M. S. Wang and Y. F. Yao, "Development situation and Countermeasures of oil and gas industry under the constraint of carbon neutralization," Petroleum Drilling Techniques, vol. 49, no. 5, pp. 1-6, 2021.

[4] C.-M. Li and R. Nie, "An evaluating system for scientific mining of China's coal resources," Resources Policy, vol. 53, pp. 317-327, 2017.

[5] X.-M. Chen, Q.-M. Liang, L.-C. Liu, C. Wang, and M.-M. Xue, "Critical structural adjustment for controlling China's coal demand," Journal of Cleaner Production, vol. 235, pp. 317327, 2019.

[6] B. Yang, K. Xu, and Z. Zhang, "Mitigating evaporation and desiccation cracks in soil with the sustainable material biochar," Soil Science Society of America Journal, vol. 84, no. 2, pp. 461-471, 2020.

[7] B. Yuan, Z. Li, Z. Zhao, H. Ni, Z. Su, and Z. Li, "Experimental study of displacement field of layered soils surrounding laterally loaded pile based on transparent soil," Journal of Soils and Sediments, vol. 21, no. 9, pp. 3072-3083, 2021.

[8] B. X. Yuan, Z. H. Li, Z. L. Su, Q. Z. Luo, M. J. Chen, and Z. Q. Zhao, "Sensitivity of multistage fill slope based on finite element model," Advances in Civil Engineering, vol. 2021, Article ID 6622936, 13 pages, 2021.

[9] M. Z. Naghadehi, R. Mikaeil, and M. Ataei, "The application of fuzzy analytic hierarchy process (FAHP) approach to selection of optimum underground mining method for Jajarm bauxite Mine, Iran," Expert Systems with Applications, vol. 36, no. 4, pp. 8218-8226, 2009.

[10] M. Yavuz, "The application of the analytic hierarchy process (AHP) and Yager's method in underground mining method selection problem," International Journal of Mining, Reclamation and Environment, vol. 29, no. 6, pp. 453-475, 2015.

[11] S.-s. Shi, S.-c. Li, L.-p. Li, Z.-q. Zhou, and J. Wang, "Advance optimized classification and application of surrounding rock based on fuzzy analytic hierarchy process and Tunnel Seismic Prediction," Automation in Construction, vol. 37, pp. 217-222, 2014.

[12] X. X. Chen, R. H. Chen, K. Lin, and M. W. Zhang, “Application of the improved analytic hierarchy process in the risk management of tunnel construction," in Applied Mechanics and Materialsp. 696, Trans Tech Publications Ltd, Kapellweg, SZ, Switzerland, 2015.

[13] V. N. Kazakidis, Z. Mayer, and M. J. Scoble, "Decision making using the analytic hierarchy process in mining engineering," Mining Technology, vol. 113, no. 1, pp. 30-42, 2004.

[14] A. Bi, Z. Luo, Y. Kong, and L. Zhao, "Comprehensive weighted matter-element extension method for the safety evaluation of underground gas storage," Royal Society Open Science, vol. 7, no. 4, Article ID 191302, 2020.

[15] N. Wang, C.-s. Xu, X.-l. Du, and M.-j. Zhang, "A risk assessment method of deep excavation based on Bayesian analysis and expert elicitation," International Journal of System Assurance Engineering and Management, vol. 9, no. 2, pp. 452-466, 2018.

[16] C. Liu, S. Yang, Y. Cui, and Y. Yang, "An improved risk assessment method based on a comprehensive weighting algorithm in railway signaling safety analysis," Safety Science, vol. 128, Article ID 104768, 2020.

[17] B. Meng and G. Chi, "New combined weighting model based on maximizing the difference in evaluation results and its application," Mathematical Problems in Engineering, vol. 2015, Article ID 239634, 9 pages, 2015.

[18] B. B. Yang, S. Yuan, Y. Liang, and J. Liu, "Investigation of overburden failure characteristics due to combined mining: case study, Henan Province, China," Environmental Earth Sciences, vol. 80, 2021.

[19] B. Yuan, Z. H. Li, Y. Chen et al., "Mechanical and microstructural properties of recycling granite residual soil reinforced with glass fiber and liquid-modified polyvinyl alcohol polymer-sciencedirect," Chemosphere, vol. 268, Article ID 131652, 2021.

[20] B. Yang, J. Liu, X. Zhao, and S. Zheng, "Evaporation and cracked soda soil improved by fly ash from recycled materials," Land Degradation \& Development, vol. 32, no. 9, pp. 2823-2832, 2021.

[21] B. Yang, D. Li, S. Yuan, and L. Jin, "Role of biochar from corn straw in influencing crack propagation and evaporation in sodic soils," Catena, vol. 204, Article ID 105457, 2021.

[22] Z. Gao, "Sustainable development and upgrading mode of coal industry in China," International Journal of Mining Science and Technology, vol. 22, no. 3, pp. 335-340, 2012.

[23] Y. Li, B. Zhang, B. Wang, and Z. Wang, "Evolutionary trend of the coal industry chain in China: evidence from the analysis of I-O and APL model," Resources, Conservation and Recycling, vol. 145, pp. 399-410, 2019.

[24] L.-T. Zhao, Z.-T. Liu, and L. Cheng, "How will China's coal industry develop in the future? a quantitative analysis with policy implications," Energy, vol. 235, Article ID 121406, 2021. 